\title{
Analisa Manajemen Resiko Keamanan Informasi pada Kantor Pelayanan Pajak Pratama XYZ
}

\author{
Iwan Santosa ${ }^{1}$, Dwi Kuswanto ${ }^{2}$ \\ 1,2Program Studi Teknik Informatika, Universitas Trunojoyo Madura \\ 1iwan@trunojoyo.ac.id, ${ }^{2}$ dwikuswanto@if.trunojoyo.ac.id
}

\begin{abstract}
ABSTRAK
Penggunaan Teknologi Informasi di lembaga-lembaga pemerintahan saat ini sangat dibutuhkan untuk mempermudah melakukan pendataan dan pengambilan keputusan yang strategis. Kantor Pelayanan Pajak Pratama XYZ yang merupakan salah satu lembaga pemerintahan yang bergerak dibidang keuangan memiliki data yang cukup banyak. Penggunaan Teknologi informasi bukan sekedar penting tapi sudah menjadi keharusan, melihat Pajak merupakan salah satu pendapatan negara yang utama. Data dan informasi yang terdapat pada Lembaga ini tidak hanya perlu penyimpanan secara digital akan tetapi juga memerlukan pengamanan yang serius. Kebocoran akan data yang ada dapat berakibat fatal bagi kepentingan negara. Untuk itu Sistem Manajemen Keamanan Informasi(SMKI) diperlukan dalam pengelolaan keamanannya. Dalam mengimplementasikan ISO 27001 sebelumnya diperlukan manajemen resiko keamanan informasi. Kegiatan manajemen resiko ini diperlukan untuk menentukan Control Objectives yang akan diambil untuk melakukan penanganan resiko yang kemungkinan terjadi. Dalam mengimplementasikan manajemen resiko didapatkan hasil hanya pada aset username dan password level yang resikonya High (6,67\%) dari 15 aset yang sudah terdaftar, sehingga diperlukan kontrol keamanan yang berhubungan dengan username dan password untuk meminimalisir atau mengurangi terjadinya resiko.
\end{abstract}

Kata Kunci: Manajemen resiko,SMKI, iso 27001.

\section{ANALYSIS OF INFORMATION SECURITY RISK MANAGEMENT IN TAX SERVICE OFFICE PRATAMA XYZ}

\begin{abstract}
Use of Information Technology in government institutions at this time is needed to make it easier to collect data and strategic decision making. KPP Pratama XYZ which is one of the government agencies engaged in finance have enough data. The use of information technology is not just important but has become imperative, see Tax is one of the main income of the country. The data and information contained in this Organization not only need a digital storage but also require security seriously. Leakage will be the existing data can be fatal to the interests of the state. For the Information Security Management System (ISMS) is required in the management of safety. In previously required to implement ISO 27001 information security risk management. Risk management activities is necessary to determine the Control Objectives that will be taken to have addressed the risk probabilities. In implementing risk management on assets showed only a username and password High risk level (6,67\%) of 15 assets that are registered, so that the necessary security controls associated with a username and password to minimize or reduce the risk.
\end{abstract}

Keywords: Risk Management,SMKI, ISO 27001. 


\section{PENDAHULUAN}

Keamanan data elektronik menjadi hal yang sangat penting di perusahaan penyedia jasa teknologi informasi (TI) maupun industri lainnya, seperti: perusahaan exportimport, tranportasi, lembaga keuangan, pendidikan, pemberitaan, hingga perbankan yang menggunakan fasilitas TI dan menempatkannya

infrastruktur kritikal (penting).

Informasi atau data adalah aset bagi perusahaan. Keamanan data secara tidak langsung dapat memastikan kontinuitas bisnis, mengurangi resiko, mengoptimalkan return on investment dan mencari kesempatan bisnis. Semakin banyak informasi perusahaan yang disimpan, dikelola dan disharing maka semakin besar pula resiko terjadinya kerusakan, kehilangan atau tereksposnya data ke pihak eksternal yang tidak diinginkan.

Bagaimana data atau informasi tersebut dikelola, dipelihara dan diekspose, melatarbelakangi disusunnya ISO 17799, standar untuk sistem manajemen keamanan informasi. Penyusunan standar ini berawal pada tahun 1995, dimana sekelompok perusahaan besar seperti BOC, BT, Marks \& Spencer, Midland Bank, Nationwide Building Society, Shell dan Unilever bekerja sama untuk membuat suatu standar yang dinamakan BS (British Standard) 7799. BS 7799 Part 1: the Code of Practice for Information Security Management. Februari 1998 BS 7799 Part 2: The Specification for Information Security Management Systems (ISMS) menyusul diterbitkan.
Desember 2000 ISO (International Organization of Standardization) dan IEC (International ElectroTechnical Commission) mengadopsi BS 7799 Part 1 dan menerbitkannya sebagai standar ISO/IEC 17799:2000 yang diakui secara internasional.

Keamanan informasi terdiri dari perlindungan terhadap aspekaspek berikut:

1. Confidentiality (kerahasiaan) aspek yang menjamin kerahasiaan data atau informasi, memastikan bahwa informasi hanya dapat diakses oleh orang yang berwenang dan menjamin kerahasiaan data yang dikirim, diterima dan disimpan.

2. Integrity (integritas) aspek yang menjamin bahwa data tidak dirubah tanpa ada ijin fihak yang berwenang (authorized), menjaga keakuratan dan keutuhan informasi serta metode prosesnya untuk menjamin aspek integrity ini.

3. Availability (ketersediaan) aspek yang menjamin bahwa data akan tersedia saat dibutuhkan, memastikan user yang berhak dapat menggunakan informasi dan perangkat terkait (aset yang berhubungan bilamana diperlukan). Keamanan informasi diperoleh dengan mengimplementasi seperangkat alat kontrol yang layak, yang dapat berupa kebijakan-kebijakan, praktekpraktek, prosedur-prosedur, struktur-struktur organisasi dan piranti lunak (Syafrizal,2007).

Sebelum menerapkan kontrol keamanan, perlu dilakukan manajemen resiko supaya dapat memaksimalkan pemilihan kontrol keamanan. Dalam penelitian ini telah dilakukan analisa resiko terhadap aset yang ada. 


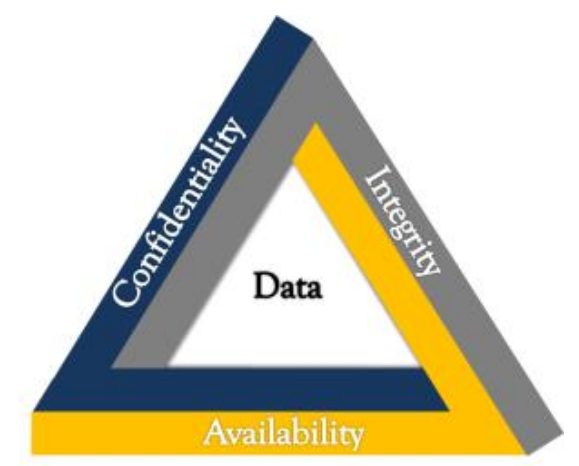

Gambar 1. Keamana informasi (CIA)

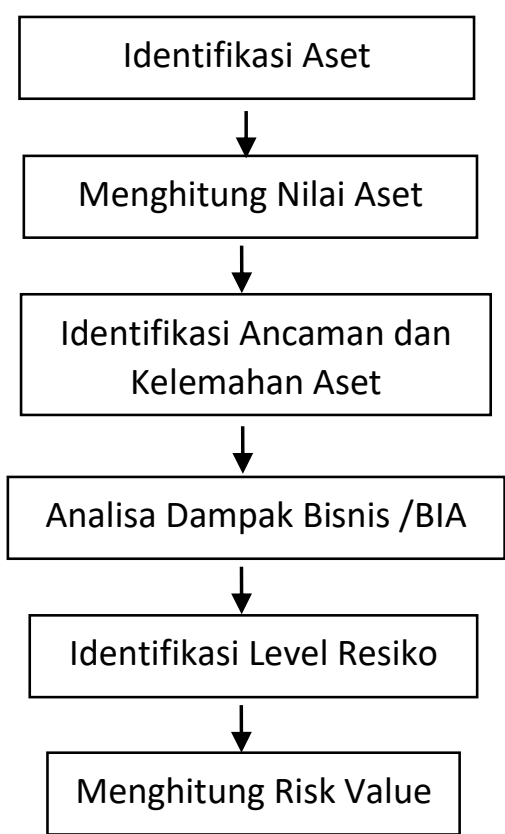

Gambar 2. Diagram Alir Penelitian

\section{METODE PENELITIAN}

Pada pembahasan ini akan dijelaskan metodologi dalam penelitian ini mulai dari pengumpulan data untuk melakukan identifikasi aset, melakukan perhitungan Nilai aset yang telah dikumpuklan, melakukan identifikasi ancaman dan kelemahan aset, melakukan analisa dampak bisnis atau yang sering disebut Business Impact Analysis (BIA), melakukan identifikasi level resiko dan yang terakhir menghitung risk value untuk mengetahui level resiko dari aset.
Tabel 1. Kriteria Convidentiality

\begin{tabular}{cc}
\hline $\begin{array}{c}\text { Kriteria } \\
\text { Cinvidentiality }\end{array}$ & $\begin{array}{c}\text { Nilai } \\
\text { Convidentiality } \\
\text { (NC) }\end{array}$ \\
\hline Public & 0 \\
Internal use only & 1 \\
Private & 2 \\
Convidential & 3 \\
Secret & 4 \\
\hline
\end{tabular}

Tabel 2. Kriteria Integrity

\begin{tabular}{cc}
\hline Kriteria Integrity & $\begin{array}{c}\text { Nilai Integrity } \\
(\mathrm{NI})\end{array}$ \\
\hline No Impact & 0 \\
Minor Incident & 1 \\
General Disturbance & 2 \\
Mayor Disturbance & 3 \\
Unacceptable & 4 \\
damage & \\
\hline
\end{tabular}

Tabel 3. Kriteria Availability

\begin{tabular}{cc}
\hline Kriteria Availability & $\begin{array}{c}\text { Nilai } \\
\text { Availability } \\
(N V)\end{array}$ \\
\hline No Availability & 0 \\
Office Hour & 1 \\
Availability & \\
Strong Availability & 2 \\
High availability & 3 \\
Very High Availability & 4 \\
\hline
\end{tabular}

Tahap awal penelitian ini adalah mengumpulkan data aset yaitu aset yang mengandung data dan atau informasi. Identifikasi Aset dilakukan untuk menentukan aset yang berhubungan dengan kontrol akses di KPP Pratama XYZ.

Setelah aset teridentifikasi, langkah selanjutnya yaitu melakukan perhitungan nilai aset. Pendekatan yang dilakukan dengan menggunakan tiga aspek keamanan, yaitu kerahasiaan (confidentiality), keutuhan (Integrity) dan ketersediaan (availiability). 
Perhitungannya dilakukan dengan menggunakan rumus :

$$
\begin{aligned}
& N A=N C+N I+N V \\
& N A: \text { Nilai Aset } \\
& N C: \text { Nilai Convidentiality } \\
& N I: \text { Nilai Integrity } \\
& N A: \text { Nilai Avaliability }
\end{aligned}
$$

Perhitungan selanjutnya
adalah melakukan identifikasi
ancaman dan kelemahan terhadap
masing-masing aset, kemudian
menentukan nilai rerata probabilitas
kemunculan ancaman dan
kelemahan dengan menggunakan
rentang nilai sebagai berikut:
1. Low
$: 0,0-0,3$
2. Medium
$: 0,4-0,6$
3. High
$: 0,7-1,0$

Langkah selanjutnya adalah menentukan analisa dampak bisnis atau yang sering disebut Business Impact Analysis (BIA). Kriteria penilaian untuk BIA dapat dilihat pada tabel 4 dibawah ini :

Penilaian level resiko menggunakan matriks resiko seperti Tabel 5. Nilai yang didapatkan berasal dari perkalian antara Probability of threat (probabilitas ancaman) dengan dampak bisnis BIA.

Tabel 4. Kriteria Nilai BIA

\begin{tabular}{ccc}
\hline $\begin{array}{c}\text { Batas } \\
\text { Toleransi } \\
\text { gangguan }\end{array}$ & Keterangan & $\begin{array}{c}\text { Nilai } \\
\text { BIA }\end{array}$ \\
\hline$<1$ minggu & Not critical $(\mathrm{NC})$ & 0 \\
$1-2$ hari & Minor critical $(\mathrm{MiC})$ & 1 \\
$<1$ hari & Mayor critical $(\mathrm{MaC})$ & 2 \\
$<12$ jam & High critical $(\mathrm{HC})$ & 3 \\
$<1$ jam & Very high & 4 \\
& critical(VHC) & \\
\hline
\end{tabular}

Tabel 5. Matrik Level Resiko

\begin{tabular}{cccccc}
\hline \multirow{2}{*}{ Prob. } & \multicolumn{6}{c}{ Dampak Bisnis } \\
Threat & NC & MiC & MaC & HC & VHC \\
& 0 & 1 & 2 & 3 & 4 \\
\hline Low & LOW & LOW & LOW & LOW & LOW \\
$(0,1)$ & 0 & 0,1 & 0,2 & 0,3 & 0,4 \\
Med & LOW & MED & MED & MED & MED \\
$(0,5)$ & 0 & 0,5 & 1,0 & 1,5 & 2,0 \\
High & LOW & MED & MED & HIGH & HIGH \\
$(1,0)$ & 0 & 1,0 & 2,0 & 3,0 & 4,0 \\
\hline
\end{tabular}

Untuk menentukan apakah resiko diterima atau diperlukan pengelolaan resiko maka perlu menghitung nilai dari resiko yang ada. Nilai Resiko dapat dihitung dengan menggunakan rumus :

Risk Value $=$ NA $X$ BIA X NT

Keterangan :

NA : Nilai Aset

BIA : Business Impact Analysis

NT : Nilai Threat

Setelah mendapatkan nilai resiko, level resiko didapatkan dengan menyesuaikan nilai resiko dengan Tabel 5 Matrik Level Resiko.

Hasil yang didapatkan setiap aset akan teridentifikasi tingkat level resikonya. Level resiko berdasarkan Tabel tersebut menunjukkan Low, Medium atau High. Dari hasil tersebut aset yang akan dilakukan pengelolaan resiko adalah aset yang beresiko High.

\section{HASIL DAN PEMBAHASAN}

Berdasarkan pengambilan
data dengan wawancara dan
observasi di KPP Pratama XYZ
didapatkan data aset seperti terlihat
pada Tabel 6. Daftar Aset dibagi
menjadi jenis Aset yang terdiri dari
perangkat keras, perangkat lunak
dan Data.


Tabel 6. Aset

\begin{tabular}{cll}
\hline No & Jenis Aset & \multicolumn{1}{c}{ Aset } \\
\hline 1 & Perangkat & PC, Server, \\
& Keras & Jaringan fisik Kabel \\
& & Kamera \\
& & CCTV,DVR CCTV \\
& & Cisco Router \\
2 & Perangkat & ESPT,EFAKTUT,EF \\
& Lunak & ILING,EBILING, \\
& & SIM-Kepegawaian, \\
& & SIM-WP, SIM- \\
& & Pajak,WEB-Server \\
3 & Data & Username dan \\
& & Password \\
\hline
\end{tabular}

Dari data aset yang telah didapatkan selanjutnya menghitung nilai aset, dan dari hasil observasi dan wawancara didapatkan nilai aset yang teridentifikasi seperti tabel 7 dibawah ini.

Langkah selanjutnya adalah mengidentifikasi kelemahan dan ancaman untuk mendapatkan Nilai Threat (NT). Hasil identifikasinya terlihat pada tabel 8 .
Tabel 7. Nilai Aset

\begin{tabular}{|c|c|c|c|c|c|}
\hline \multirow[b]{2}{*}{ No } & \multirow[b]{2}{*}{ Aset } & \multicolumn{3}{|c|}{ Kriteria } & \multirow{2}{*}{$\begin{array}{l}\text { Nilai } \\
\text { Aset }\end{array}$} \\
\hline & & $\mathrm{NC}$ & $\mathrm{NI}$ & NV & \\
\hline 1 & PC & 2 & 1 & 2 & 5 \\
\hline 2 & Server & 4 & 4 & 4 & 12 \\
\hline 3 & $\begin{array}{l}\text { Jaringan } \\
\text { Fisik Kabel }\end{array}$ & 3 & 2 & 3 & 8 \\
\hline 4 & $\begin{array}{l}\text { Kamera } \\
\text { CCTV }\end{array}$ & 2 & 2 & 2 & 6 \\
\hline 5 & DVDR CCTV & 2 & 2 & 2 & 6 \\
\hline 6 & Cisco Router & 3 & 2 & 4 & 9 \\
\hline 7 & ESPT & 3 & 3 & 3 & 9 \\
\hline 8 & EFAKTUT & 3 & 3 & 3 & 9 \\
\hline 9 & EFILLING & 3 & 2 & 3 & 8 \\
\hline 10 & EBILLING & 3 & 2 & 2 & 7 \\
\hline 11 & $\begin{array}{l}\text { SIM- } \\
\text { Kepegawaian }\end{array}$ & 2 & 2 & 2 & 6 \\
\hline 12 & SIM-WP & 2 & 2 & 3 & 7 \\
\hline 13 & SIM-Pajak & 3 & 3 & 3 & 9 \\
\hline 14 & Web Server & 4 & 3 & 3 & 10 \\
\hline 15 & $\begin{array}{l}\text { Data User } \\
\text { dan } \\
\text { Password }\end{array}$ & 4 & 3 & 3 & 10 \\
\hline
\end{tabular}

Tabel 8. Probabilitas dan Nilai Ancaman (NT)

\begin{tabular}{|c|c|c|c|c|c|c|c|}
\hline Aset & Kejadian & $\begin{array}{c}\text { Jenis } \\
\text { ancaman/ } \\
\text { kelemahan }\end{array}$ & $\begin{array}{l}\text { Prob. } \\
\text { (low/ } \\
\text { med/ } \\
\text { high) }\end{array}$ & Event & $\begin{array}{l}\text { Nilai } \\
\text { Prob. }\end{array}$ & $\sum_{P O}$ & NT \\
\hline PC & Pencurian PC & ancaman & low & 0 & 0 & 0 & - \\
\hline \multirow{2}{*}{ Server } & Pencurian PC & ancaman & low & 0 & 0 & \multirow{2}{*}{0} & \multirow{2}{*}{-} \\
\hline & Illegal Akses & ancaman & low & 0 & 0 & & \\
\hline \multirow{2}{*}{ Jaringan } & Illegal Akses & ancaman & low & 0 & 0 & \multirow{2}{*}{0} & \multirow{2}{*}{-} \\
\hline & Pencurian PC & ancaman & low & 0 & 0 & & \\
\hline \multirow{3}{*}{$\begin{array}{c}\text { Kamera } \\
\text { CCTV }\end{array}$} & Pencurian PC & ancaman & low & 0 & 0 & \multirow{2}{*}{0} & \multirow{2}{*}{-} \\
\hline & Perusakan & ancaman & low & 0 & 0 & & \\
\hline & Pencurian Perangkat & ancaman & low & 0 & 0 & \multirow{3}{*}{0} & \multirow{3}{*}{ - } \\
\hline \multirow[t]{2}{*}{ DVDR CCTV } & Perusakan & ancaman & low & 0 & 0 & & \\
\hline & Pencurian Rekaman & ancaman & low & 0 & 0 & & \\
\hline \multirow{2}{*}{$\begin{array}{l}\text { Cisco } \\
\text { Router }\end{array}$} & Illegal Akses & ancaman & low & 0 & 0 & \multirow{2}{*}{0} & \multirow{2}{*}{-} \\
\hline & Pencurian & ancaman & low & 0 & 0 & & \\
\hline \multirow{3}{*}{ ESPT } & Aplikasi tidak terupdate & kelemahan & low & 0 & 0 & \multirow{3}{*}{0.4} & \multirow{3}{*}{0.13} \\
\hline & serangan Virus & ancaman & low & 3 & 0.15 & & \\
\hline & Kegagalan Operasional & kelemahan & low & 5 & 0.25 & & \\
\hline
\end{tabular}




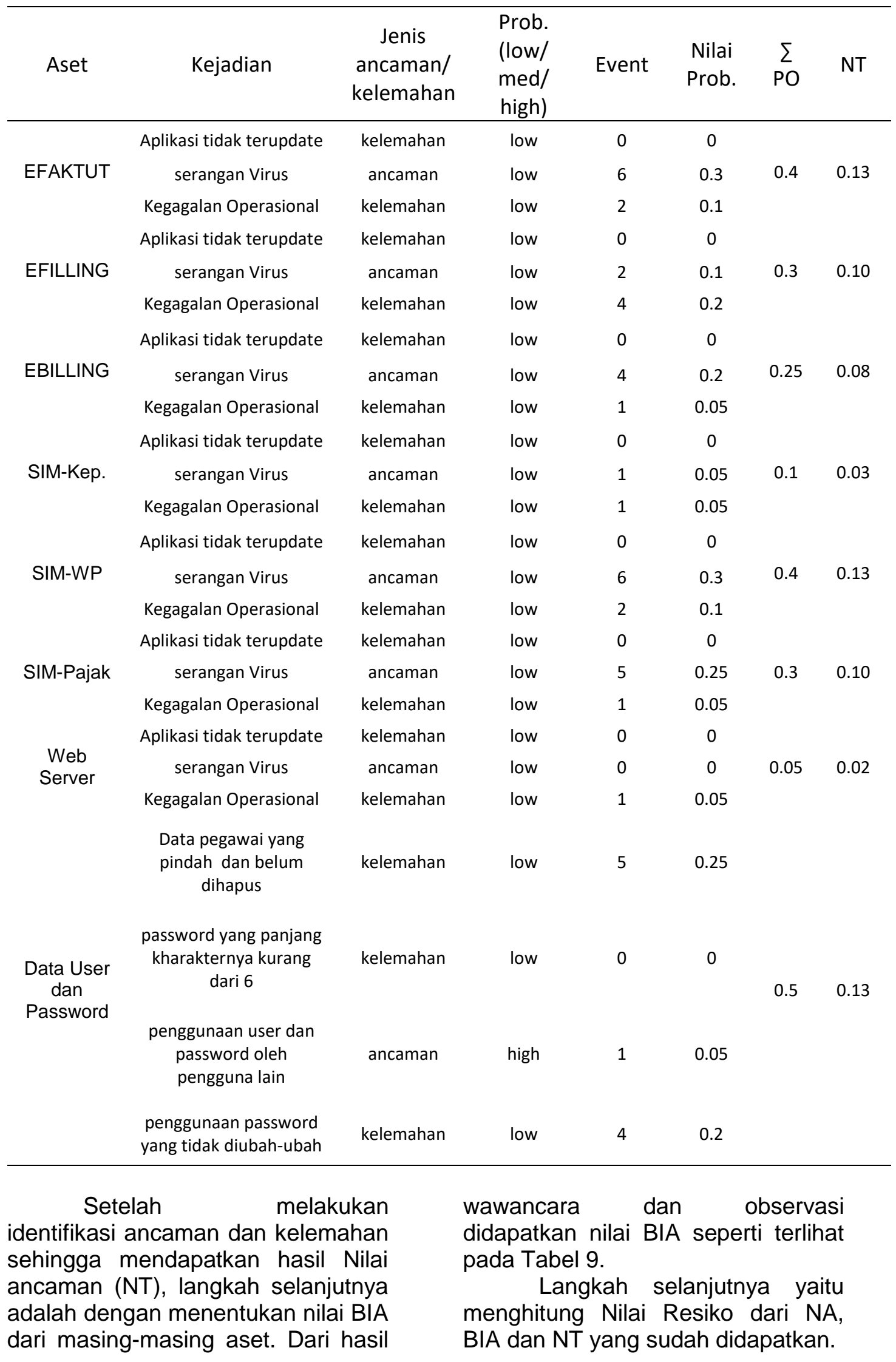


Tabel 9. BIA

\begin{tabular}{lr}
\hline Aset & Nilai BIA \\
\hline PC & 1 \\
Server & 4 \\
Jaringan Fisik Kabel & 2 \\
Kamera CCTV & 1 \\
DVDR CCTV & 1 \\
Cisco Router & 3 \\
ESPT & 2 \\
EFAKTUT & 2 \\
EFILLING & 2 \\
EBILLING & 2 \\
SIM-Kepegawaian & 3 \\
SIM-WP & 3 \\
SIM-Pajak & 3 \\
Web Server & 4 \\
Data User dan & 3 \\
Password & \\
\hline
\end{tabular}

Dengan menggunakan Tabel 5 tentang matrik resiko akan didapatkan hasil level resiko. Hasil perhitungan dan level resiko terlihat pada tabel 10.
Dari tabel 10 didapatkan aset yang memiliki resiko tinggi dan diperlukan kontrol keamanan untuk mengurangi resiko yang terjadi adalah Data User dan Password dengan prosentase $6,67 \%$ dari data Aset yang terdaftar, $26,67 \%$ memiliki level Medium serta 66,67 memiliki level High.

\section{KESIMPULAN}

Dari hasil penelitian yang telah dilakukan dapat disimpulkan bahwa dari aset yang terdaftar hanya satu aset yang memiliki resiko High yaitu Data Username dan Password dengan prosentase $6,67 \%$.

Untuk meningkatkan kualitas penelitian diperlukan analisa yang lebih banyak dari jenis kejadian, sehingga hasil analisanya lebih mendalam. Rekomendasi lainya yaitu penelitian dapat dilanjutkan kepada pemilihan kontrol keamanan dalam rangka menyusun portofolio SMKI.

Tabel 10. Nilai Resiko dan Level Resiko

\begin{tabular}{clccccc}
\hline No & Aset & Nilai Aset & Nilai Ancaman & BIA & Nilai Resiko & Level Resiko \\
\hline 1 & PC & 5 & 0 & 1 & 0 & low \\
2 & Server & 12 & 0 & 4 & 0 & low \\
3 & Jaringan Fisik Kabel & 8 & 0 & 2 & 0 & low \\
4 & Kamera CCTV & 6 & 0 & 1 & 0 & low \\
5 & DVDR CCTV & 6 & 0 & 1 & 0 & low \\
6 & Cisco Router & 9 & 0 & 3 & 0 & low \\
7 & ESPT & 9 & 0.13 & 2 & 2.34 & med \\
8 & EFAKTUT & 9 & 0.13 & 2 & 2.34 & med \\
9 & EFILLING & 8 & 0.1 & 2 & 1.6 & low \\
10 & EBILLING & 7 & 0.08 & 2 & 1.12 & low \\
11 & SIM-Kepegawaian & 6 & 0.03 & 3 & 0.54 & low \\
12 & SIM-WP & 7 & 0.13 & 3 & 2.73 & med \\
13 & SIM-Pajak & 9 & 0.1 & 3 & 2.7 & med \\
14 & Web Server & 10 & 0.02 & 4 & 0.8 & low \\
15 & Data User dan Password & 10 & 0.13 & 3 & 3.9 & high \\
\hline
\end{tabular}




\section{DAFTAR PUSTAKA}

Syafrizal, M., Seminar Nasional Teknologi 2007 (SNT 2007), Yogyakarta, 24 November 2007.

Sarno, R. 2009. Audit Sistem \& Teknologi

Informasi.Surabaya: ITS Press 2 ISO/IEC 27001:2005, Information Technology Security Techniques Information Security Management System Requirements, 15 Oktober 2005

Sarno, R., Iffano, Irsyat 2009. Sistem Manajemen Keamanan Informasi berbasis ISO 27001. Surabaya: ITS Press.
Utomo, M.,Ali, A. H. N.,Affandi, I. (2012). Pembuatan Tata Kelola Keamanan Informasi Kontrol Akses Berbasis ISO/IEC 27001:2005 Pada Kantor Pelayanan Perbendaharaan Surabaya 1.Jurnal Teknik ITS. Vol. 1 No. 1

Rozas, I. S., Sarno, R. (2010). Bayesian Probabilistik Sebagai Pendekatan Heuristik untuk Manajemen Resiko Teknologi Informasi. Prosiding Seminar Nasional Manajemen Teknologi XII.

Aprian, R.,Rizal, S., Sobri, M.(2015).Perencanaan

Sistem Manajemen

Keamanan Informasi

Menggunakan Standar ISO 27001:2013. Jurnal Informatika 